\title{
ROLE OF THE ALLELIC VARIATION IN THE 5-HYDROXYTRYPTAMINE RECEPTOR 1A (HTR1A) AND THE TRYPTOPHAN HYDROXYLASE 2 (TPH2) GENES IN THE DEVELOPMENT OF PTSD
}

\author{
Afërdita Goçi Uka ${ }^{1}$, Ferid Agani ${ }^{2}$, Afrim Blyta ${ }^{2}$, Blerina Hoxha ${ }^{1}$, Shpend Haxhibeqiri ${ }^{3}$, \\ Valdete Haxhibeqiri ${ }^{4}$, Emina Sabic Dzananovic ${ }^{5}$, Sabina Kucukalic ${ }^{5}$, Alma Bravo Mehmedbasic ${ }^{5}$, \\ Abdulah Kucukalic ${ }^{5}$, Alma Dzubur-Kulenovic ${ }^{5}$, Elma Feric Bojic ${ }^{6}$, Damir Marjanovic ${ }^{6,12}$, \\ Nermina Kravic $^{7}$, Esmina Avdibegovic ${ }^{7}$, Mirnesa Muminovic Umihanic ${ }^{8}$, Nenad Jaksic ${ }^{9}$, \\ Ana Cima Franc', Dusko Rudan ${ }^{9}$, Miro Jakovljevic ${ }^{9}$, Romana Babic ${ }^{10}$, Marko Pavlovic ${ }^{10}$, \\ Dragan Babic $^{10}$, Branka Aukst Margetic ${ }^{11}$, Nada Bozina ${ }^{13}$, Osman Sinanovic ${ }^{14}$, \\ Christiane Ziegler ${ }^{15}$, Bodo Warrings ${ }^{16}$, Katharina Domschke ${ }^{15}$, Jürgen Deckert ${ }^{16}$ \& Christiane Wolf $^{16}$ \\ ${ }^{1}$ Department of Psychiatry, University Clinical Center of Kosovo, Prishtina, Kosovo \\ ${ }^{2}$ Faculty of Medicine, University Hasan Prishtina, Prishtina, Kosovo \\ ${ }^{3}$ Institute of Kosovo Forensic Psychiatry, University Clinical Center of Kosovo, Prishtina, Kosovo \\ ${ }^{4}$ Department of Medical Biochemistry, University Clinical Center of Kosovo, Prishtina, Kosovo \\ ${ }^{5}$ Department of Psychiatry, University Clinical Center, Sarajevo, Bosnia and Herzegovina \\ ${ }^{6}$ Department of Genetics and Bioengineering, International Burch University, Sarajevo, Bosnia and Herzegovina \\ ${ }^{7}$ Department of Psychiatry, University Clinical Center of Tuzla, Tuzla, Bosnia and Herzegovina \\ ${ }^{8}$ Community Health Center Zivinice, Zivinice, Bosnia and Herzegovina \\ ${ }^{9}$ Department of Psychiatry, University Hospital Center Zagreb, Zagreb, Croatia \\ ${ }^{10}$ Department of Psychiatry, University Clinical Center of Mostar, Mostar, Bosnia and Herzegovina \\ ${ }^{11}$ Department of Psychiatry, University Hospital Sestre Milosrdnice, Zagreb, Croatia \\ ${ }^{12}$ Institute for Anthropological Researches, Zagreb, Croatia \\ ${ }^{13}$ Department of Laboratory Diagnostics, University Hospital Center Zagreb, Zagreb, Croatia \\ ${ }^{14}$ Department of Neurology, University Clinical Center of Tuzla, Tuzla, Bosnia and Herzegovina \\ ${ }^{15}$ Department of Psychiatry and Psychotherapy, Medical Center, University of Freiburg, \\ Faculty of Medicine, University of Freiburg, Germany \\ ${ }^{16}$ Department of Psychiatry, Psychosomatics and Psychotherapy, University of Würzburg, Würzburg, Germany
}

received: 4.2.2019;

revised: 22.5.2019;

accepted: 28.5.2019

\section{SUMMARY}

Background: Post-traumatic stress disorder (PTSD) is a stress related disorder which can occur in an individual after exposure to a traumatic event. It most commonly co-occurs with depression. The two disorders share not only overlapping symptoms, but also genetic diathesis. The aim of this study was to investigate the potential role of single nucleotide polymorphisms (SNPS) of the two serotonergic candidate genes 5-hydroxytryptamine receptor 1 A (HTR1A) and tryptophan hydroxylase 2 (TPH2) in the pathogenesis of PTSD and comorbid psychopathology.

Subjects and methods: 719 (487 males, 232 females) participants who had experienced war-related trauma between 1991 and 1999 in Bosnia and Herzegovina, Kosovo and Croatia were included in the study. The Sociodemographic questionnaire, Mini International Neuropsychiatric Interview (M.I.N.I.), Clinician Administered PTSD Scale (CAPS) and Brief Symptom Inventory (BSI) were used to collect clinical data. The SNPs rs6295 (HTR1A), rs11178997 and rs1386494 (TPH2) were investigated for their association with PTSD and comorbid psychopathology.

Results: A nominal significant association was found between the BSI total score in Lifetime PTSD with the SNP rs6295 of the HTRIA gene. The best result was seen in the dominant model $(P=0.018)$, with the minor allele $(C)$ being the risk allele. Several BSI subscores were also associated with the minor $(C)$ allele in Lifetime PTSD. No association was found for the TPH2 SNPS rs11178997 and rs 1386494 in relation to PTSD or comorbid psychopathology.

Conclusions: Our findings suggest that rs6295 in the HTR1A gene may contribute to the psychopathology of PTSD.

Key words: PTSD - single nucleotide polymorphisms - 5-hydroxytryptamine receptor 1 A - tryptophan hydroxylase2

$$
* * * * *
$$

\section{INTRODUCTION}

Post-Traumatic stress disorder (PTSD), is a stress related disorder which can occur in an individual after exposure to a traumatic event. In DSM-5, the symptoms of PTSD are grouped in 4 clusters: intrusion symptoms, avoidance, negative alterations in cognitions and mood, alteration in arousal and reactivity (APA 2013). The majority of people experience some traumatic event at some point in their life. The frequency of any exposure 
to traumatic events for an individual was reported to range from $76 \%$ (Norris et al. 2003) to $89.7 \%$ (Kilpatrick et al. 2013). In spite of this high occurrence of trauma exposure, the estimated lifetime prevalence of PTSD is not equivalently raised. In the general US population, the lifetime prevalence of PTSD was reported to be at $7.8 \%$ in a study conducted by Kessler et al. in 1995 , and at $8.3 \%$ in a newer study conducted by Kilpatrick et al. in 2013, while the lifetime prevalence of combat related PTSD in the US studies ranges from 6-31\% (Richardson et al. 2010).

In war torn countries the frequency of PTSD is high as the majority of population experiences multiple trauma. The prevalence of PTSD in Kosovo one year after the war was 25\% (Lopes Cardozo et al. 2003) while several years later Priebe et al. (2010) found the prevalence of PTSD to be $18.2 \%$ in Kosovo, $18 \%$ in Croatia and $35.4 \%$ in Bosnia and Herzegovina. Similarly, De Yong et al. (2001) found high prevalence rates ranging from $15.8 \%$ to $37.4 \%$ in a survey conducted in Ethiopia, Gaza, Cambodia and Algeria.

Since PTSD is a complex and very disabling disorder, it is important to use a multi perspective integrative model of PTSD in order to provide proper treatment and healing (Jakovljevic et al. 2012).

Studies in the recent years have shown the influence of both environmental and genetic factors on the pathogenesis of PTSD. Genetic twin studies show that PTSD has a moderate heritability of about $30-40 \%$ (Almli et al. 2014, Stein et al. 2002, Domschke 2012, Cornelis et al. 2010), and that it is a polygenic disorder (Boyajyan et al. 2015).

The serotonergic system is among the most studied pathways in candidate gene association studies in mental disorders. Some genes of the serotonergic system studied in mental disorders are the 5-hydroxytryptamine receptor 1A (HTR1A) gene and the tryptophan hydroxylase 2 (TPH2) gene.

HTR1A is a G-protein-coupled receptor and is expressed both as a presynaptic auto receptor on raphe neurons, and as a postsynaptic receptor in other structures of the brain such as the hippocampus, the frontal cortex and the hypothalamus. These brain regions are involved in mood, emotion and stress response (Savitz et al. 2009, François et al. 2008).

The single nucleotide polymorphism (SNP) rs6295 in HTR1A is one of the most investigated polymorphisms of this gene and was is associated with several disorders such as depression and suicide (Lemonde et al. 2003), panic disorder (Domschke et al. 2006), impulsivity (Benko et al. 2010), depression and bipolar disorder (Kishi et al. 2013).

Donaldson et al. (2016) found a relation between rs6295G and an increased risk for substance abuse, psychiatric hospitalization and suicide attempts, but not with trauma, while Savitz et al. (2009) concluded in their review that in humans, the frequency of the $G$ allele of rs6295 in HTR1A was increased in patients with Major depressive disorder (MDD), while the C allele was shown to be associated with a better response to antidepressant drugs.

Tryptophan hydroxylase (TPH) is the rate limiting enzyme in the synthesis of serotonin. The TPH2 isoform is found exclusively in the brain (Kennedy et al. 2012). The SNPs rs11178997 and rs1386494 within the TPH gene are investigated in relation to PTSD and depression by Goenjian et al. 2012. They found a significant association of PTSD symptoms and the T allele of the TPH2 SNP rs11178997 ( $\mathrm{p}=0.03)$, explaining $4 \%$ of the variance of PTSD, and no association with depression. The same SNP is significantly associated $(\mathrm{P}=0.001)$ with unipolar depression in a Swedish study (Van Den Bogaert et al. 2006). In 2014, Cao et al. studied the TPH2 SNP rs11178997 in relation to PTSD. They found no significant associations between this SNP and total PTSD symptoms, but the TT genotype was significantly associated with avoidance symptoms in women. Further, the SNP rs1386494 within TPH2 was found to be related to depression in a study of Zill et al. (2004).

The aim of this study was to investigate the potential role of common genetic variants of two serotonergic candidate genes, HTR1A (rs6295) and TPH2 (rs11178997 and rs1386494) in the pathogenesis of PTSD and comorbid psychopathology of PTSD.

\section{SUBJECTS AND METHODS}

\section{Subjects}

The current study is part of the project "Molecular mechanisms of post-traumatic stress disorder" which was funded by the German Academic Exchange Service (DAAD), Stability pact for South Eastern Europe. Recruitment was performed between 2013 and 2015 in 5 psychiatric centers, within three countries which have experienced war: Prishtina (Kosovo), Sarajevo, Tuzla, Mostar (Bosna and Herzegovina) and Zagreb (Croatia).

Inclusion criteria were being at least 16 years old at time of experiencing war trauma, taking into account the time of war which differed for each country: Croatia 1991-1992, Bosnia-Herzegovina 1992-1995 and Kosovo 1998-1999. The exclusion criteria were: being older then 65 , suffering from: organic brain disorders, epilepsy, oncologic disease, mental retardation, psychotic disorder, substance use disorder (except for smoking), or using medication that affects methylation such as valproic acid. Also, first and second-degree relatives were not included in the study. More detailed information regarding the study design, recruitment, diagnostic assessment, sample and gender distribution are described in detail elsewhere (Dzubur-Kulenović et al.2016).

Of the 747 recruited individuals, 719 (mean age

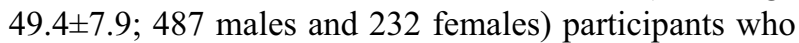
had experienced war-related trauma between 1991 and 
1999 could be included in the molecular genetics study. The experimental group comprised 218 patients (mean age $50.1 \pm 6.7 ; 157$ males and 61 females) with current PTSD, 151 participants with lifetime PTSD (mean age 49.5 \pm 8.2 ; 98 males and 53 females), and 350 participants with no diagnosable PTSD (mean age $48.8 \pm 8.5$; 232 males and 118 females).

\section{Ethical Votes}

Ethical votes at the participating clinical centers were obtained between 2011 and 2013 on the basis of local translations of an information and consent form designed by the Würzburg center.

Included in the study were only participants who signed consent letter according to the principles of the declaration of Helsinki (WMA 2013).

\section{Psychiatric Instruments}

Sociodemographic questionnaire was designed for obtaining the demographic data for purpose of the study. For screening for PTSD and other psychiatric disorders the Mini International Psychiatric Interview (M.I.N.I) was applied. Clinician Administered PTSD Scale (CAPS), a semi-structured interview, was used for identification of lifetime and current PTSD, as well as severity of PTSD. Brief Symptom inventory (BSI) was used to measure symptom dimensions of depression, somatization, obsessions and compulsions, phobic anxiety, hostility, interpersonal sensitivity, anxiety, paranoid ideation, psychoticism.

\section{Molecular Analyses}

Molecular analyses were performed at the Laboratory of the Department of Psychiatry, Psychosomatics and Psychotherapy, University of Würzburg, Germany. Genomic DNA was isolated from frozen venous EDTAblood using the FlexiGene DNA Kit (Qiagen, Hilden, Germany) according to manufacturer's instructions and stored until use at $-80^{\circ} \mathrm{C}$.

The HTR1A single nucleotide polymorphism rs6295 was genotyped as described in publication of Straube et al. 2014.

For the TPH2 gene, 2 SNP were analysed. Rs11178997 was investigated according to previously published protocols (Baehne 2009). Rs1386494 genotypes were determined by the described PCR-RFLP procedure: DNA was amplified by PCR in a $25 \mu \mathrm{l}$ reaction volume containing 45-65 ng genomic DNA, $0.4 \mathrm{mM}$ of each genomic primer (F: 5'- AAATTCTCTGTCTCTCTGATA3' and R: 5'-TGAATGGAAATAAACACAGCT-3'), $0.1 \mathrm{mM}$ of each nucleotide, $1.5 \mathrm{mM} \mathrm{MgCL}_{2}$ and $0.3 \mathrm{U}$ Taq DNA polymerase under the following cycler conditions: 5 min denaturation at $95^{\circ} \mathrm{C}$, followed by 35 cycles with $45 \mathrm{~s}$ at $95^{\circ} \mathrm{C}, 45 \mathrm{~s}$ at $54^{\circ} \mathrm{C}$ and $45 \mathrm{~s}$ at $72^{\circ} \mathrm{C}$ and a final extension step of $3 \mathrm{~min}$ at $72^{\circ} \mathrm{C}$. PCR frag- ments were digested with the restriction endonuclease BsaWI (NEB, Frankfurt a. Main, Germany) for $1.5 \mathrm{~h}$ at $60^{\circ} \mathrm{C}$ which results in differentially sized fragments representing the respective genotypes. The fragments were separated on a $3 \%$ agarose gel by electrophoresis and visualized with ethidium bromide. Fragment lengths and resulting genotypes were determined by two independent investigators blinded for diagnosis.

\section{Statistical analyses}

Statistics were performed using PLINK 1.9. All three SNPs were polymorphous (minor allele frequency $>5 \%$ ), reached a minimal genotyping call rate of $98 \%$ and did not deviate from Hardy-Weinberg equilibrium $(p>0.05)$. Logistic regression was used for case-control analyses. Within the two groups of patients, i.e. individuals with lifetime or current PTSD, linear regression was carried out for analyses on dimensional CAPS and BSI scores. The following models were tested in all phenotypes: additive allelic, dominant and the genotypic model. The significance level was Bonferroni adjusted for 23 variants that were analysed in total in the entire project $(\alpha=0.002)$.

\section{RESULTS}

To examine the contribution of HTR1A and TPH2 in the development of PTSD, the most investigated HTR1A variant rs6295, as well as the two known TPH2 SNPs rs11178997 and rs1386494 were analyzed in a case-control approach in altogether 719 participants. The influence of allelic variation on the both PTSD linked questionnaires, CAPS and BSI, was determined in all cases with diagnosed current PTSD and separately in those with lifetime PTSD symptoms.

\section{5-Hydroxytryptamine Receptor 1A}

In none of the three calculated models there was any detectable impact of the HTR1A variant rs6295 on the categorical PTSD phenotype $\left(\mathrm{P}_{\mathrm{all}}>0.05\right.$; Table 1$)$ found. When linear regression was carried out for CAPS total and BSI total scores, nominal significant associations were found only for BSI within the PTSD lifetime group, with the best result being in the dominant model $(\mathrm{P}=0.018, \beta=22.51, \mathrm{SE}=9.44$; Table 1 and Figure 1). Nominal significance was also found in the allelic model $(\mathrm{P}=0.029, \beta=13.22, \mathrm{SE}=6.00$; Table 1) and a trend to significance in the genotypic model $(\mathrm{P}=0.053$; Table 1), always with the minor allele (C) conveying genetic risk. However, results for the BSI questionnaire could not be replicated in patients with diagnosed current PTSD ( $\mathrm{P}_{\mathrm{all}}>0.05$; Table 1$)$. Analyses on CAPS total scores revealed neither for the current nor for the lifetime PTSD group any association $\left(\mathrm{P}_{\mathrm{all}}>0.05\right.$; Table 1$)$. 
Table 1. Association results of rs6295 (HTR1A) along with genotype- and allele counts, for individuals in analysis, CAPS and BSI means and standard deviations (SD), as well as nominal p-values

\begin{tabular}{|c|c|c|c|c|c|c|c|}
\hline \multirow{2}{*}{ 5HTR1A rs6295 } & \multicolumn{2}{|c|}{ Allelic Model } & \multicolumn{3}{|c|}{ Genotypic Model } & \multicolumn{2}{|c|}{ Dominant Model } \\
\hline & $\mathrm{C}$ & $\mathrm{G}$ & $\mathrm{CC}$ & $\mathrm{CG}$ & GG & $\mathrm{CC} / \mathrm{CG}$ & GG \\
\hline Controls & 328 & 362 & 84 & 160 & 101 & 244 & 101 \\
\hline PTSD $_{\text {lifetime }}$ & 148 & 152 & 33 & 82 & 35 & 115 & 35 \\
\hline PTSD $_{\text {current }}$ & 189 & 243 & 43 & 103 & 70 & 146 & 70 \\
\hline $\mathrm{P}_{\text {case-control-value }}$ & \multicolumn{2}{|c|}{0.576} & \multicolumn{3}{|c|}{0.434} & \multicolumn{2}{|c|}{0.2441} \\
\hline $\mathrm{CAPS}_{\text {lifetime }}($ mean $\pm \mathrm{SD})$ & $66.6 \pm 18.3$ & $66.6 \pm 18.3$ & $64.8 \pm 14.2$ & $69.4 \pm 18.5$ & $63.3 \pm 17.6$ & $68.1 \pm 17.5$ & $63.3 \pm 17.6$ \\
\hline $\mathrm{P}_{\mathrm{CAPS}-\text { value }}$ & \multicolumn{2}{|c|}{0.704} & \multicolumn{3}{|c|}{0.1722} & \multicolumn{2}{|c|}{0.167} \\
\hline $\mathrm{CAPS}_{\text {current }}($ mean $\pm \mathrm{SD})$ & $80.3 \pm 21.3$ & $78.3 \pm 20.5$ & $79.2 \pm 22.6$ & $81.2 \pm 20.1$ & $76.3 \pm 20.4$ & $80.6 \pm 20.9$ & $76.3 \pm 20.4$ \\
\hline $\mathrm{P}_{\mathrm{CAPS}}$-value & \multicolumn{2}{|c|}{0.349} & \multicolumn{3}{|c|}{0.321} & \multicolumn{2}{|c|}{0.157} \\
\hline $\mathrm{BSI}_{\text {lifetime }}($ mean $\pm \mathrm{SD})$ & $78.7 \pm 49.1$ & $67.1 \pm 48.4$ & $81.6 \pm 47.3$ & $76.4 \pm 50.4$ & $56.1 \pm 42.7$ & $77.8 \pm 49.6$ & $56.1 \pm 42.7$ \\
\hline $\mathrm{P}_{\mathrm{BSI}}{ }^{-v a l u e}$ & \multicolumn{2}{|c|}{0.029} & \multicolumn{3}{|c|}{0.053} & \multicolumn{2}{|c|}{0.018} \\
\hline $\mathrm{BSI}_{\text {current }}($ mean $\pm \mathrm{SD})$ & $115.6 \pm 44.7$ & $111.2 \pm 47.0$ & $114.3 \pm 43.6$ & $116.7 \pm 45.5$ & $107.3 \pm 47.9$ & $116.0 \pm 44.9$ & $107.3 \pm 47.9$ \\
\hline $\mathrm{P}_{\mathrm{BSI}}{ }^{-v a l u e}$ & \multicolumn{2}{|c|}{0.349} & \multicolumn{3}{|c|}{0.321} & \multicolumn{2}{|c|}{0.157} \\
\hline
\end{tabular}

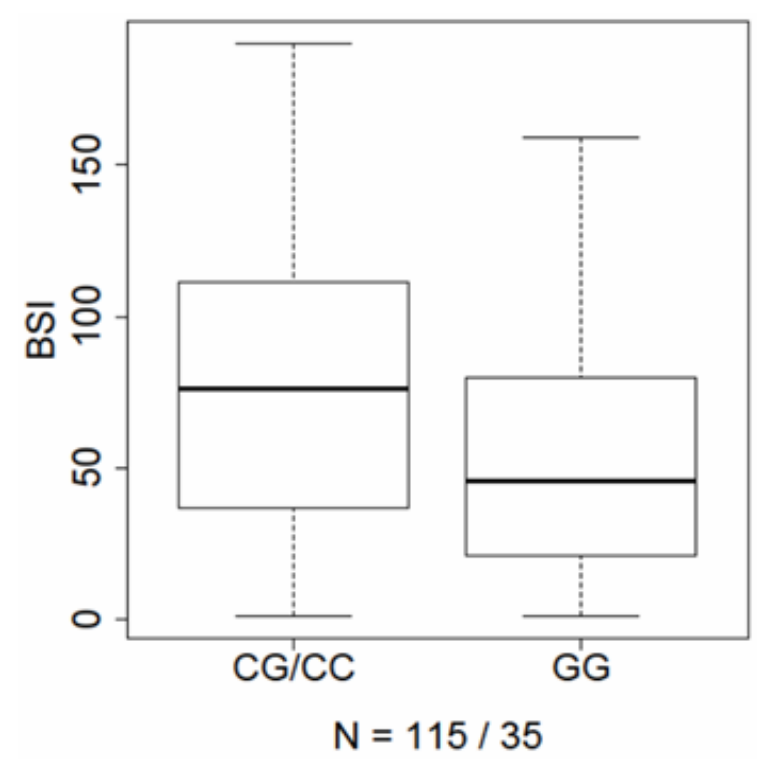

Figure 1. Boxplot showing the distribution of BSI values within the lifetime PTSD patients according to genotypes in the dominant model $(\mathrm{GC} / \mathrm{CC}$ versus $\mathrm{GG})$ for the minor allele $(\mathrm{P}=0.018)$

When tests were run for both types of PTSD (current and lifetime) with BSI subscales, we found nominal significance only for current PTSD and Obsessive-Compulsive Disorder $(\mathrm{OCD})$ in the dominant $(\mathrm{P}=0.026, \beta=0.33$, $\mathrm{SE}=0.15)$ and additive allelic $(\mathrm{P}=0.040, \beta=0.040, \mathrm{SE}=0.10)$ model. No further significant results were found for current PTSD and other subscales of BSI $\left(\mathrm{P}_{\text {all }}>0.05\right)$.

In contrast lifetime PTSD was significantly associated with depression $\left(\mathrm{P}_{\text {Dominant }}=0.031, \beta=0.44, \mathrm{SE}=0.20\right.$; $\left.\mathrm{P}_{\text {Allelic }}=0.036 . \beta=0.27, \mathrm{SE}=0.13\right)$, hostility $\left(\mathrm{P}_{\text {Dominant }}=0.043\right.$, $\left.\beta=0.42, \quad S E=0.21 ; P_{\text {Allelic }}=0.019 . \quad \beta=0.31, \quad S E=0.13\right)$, paranoid ideation $\left(\mathrm{P}_{\text {Dominant }}=0.022, \beta=0.47, \mathrm{SE}=0.20\right.$; $\left.\mathrm{P}_{\text {Allelic }}=0.029 . \quad \beta=0.28, \quad \mathrm{SE}=0.13\right), \quad$ psychoticism $\left(\mathrm{P}_{\text {Dominant }}=0.010, \beta=0.44, \mathrm{SE}=0.17 ; \mathrm{P}_{\text {Allelic }}=0.044 . \beta=0.22\right.$, $\mathrm{SE}=0.11)$, somatization $\left(\mathrm{P}_{\text {Dominant }}=0.023, \beta=0.27, \mathrm{SE}=0.12\right.$;
$\left.\mathrm{P}_{\text {Allelic }}=0.005 . \quad \beta=0.52, \mathrm{SE}=0.18\right)$ and phobic anxiety $\left(\mathrm{P}_{\text {Dominant }}=0.039, \beta=0.39, \mathrm{SE}=0.19\right)$. In all subscales again, the minor allele $(\mathrm{C})$ increased risk to develop symptoms at a nominal level.

However, none of the associations withstood Bonferroni correction for multiple tests.

\section{Tryptophan Hydroxylase 2}

No significant association between SNPs of the TPH2 gene (rs11178997 and rs1386494) and PTSD or depression were found, neither for dimensional nor for the categorical phenotypes $\left(\mathrm{P}_{\mathrm{all}}>0.05\right)$.

\section{DISCUSSION}

The aim of our study was to investigate a possible association of serotonergic candidate genes HTR1A and TPH2 with PTSD and comorbid psychopathology. We chose to investigate two serotonergic genes based on their hypothesized impact for the serotonergic system in PTSD and other mental health disorders. For the casecontrol analysis PTSD lifetime and PTSD current patients were tested together versus control individuals. For testing association with BSI and CAPS each of the two patient groups was analyzed individually.

We found a nominal significant correlation $(\mathrm{P}=0.018)$ of the BSI total score in the lifetime PTSD patients with rs6295 (HTR1A) in the dominant model. The minor allele (C) was associated with a higher BSI score. Nominally significant correlations were also found between Lifetime PTSD and BSI sub scores such as depression, hostility, paranoid ideation, psychoticism, somatization and phobic anxiety, mainly in the dominant and additive allelic model. The only nominal significant correlation for current PTSD was found in relation to OCD subscale of BSI. However, these results did not withstand Bonferroni correction. 
Our results support the findings of Donaldson et al. (2016) who did not find any significant association between HTR1A rs6295 and current PTSD or depression. The results from other candidate gene association studies that investigated the association of rs6295 with depression are inconsistent. While some studies found a significant association between this SNP and depression (Kishi et al. 2013, Lemonde et al. 2003) other studies did not observe any significant association (Chipman et al. 2010, Illi et al.2009, Hettema et al. 2008).

In our study, we did not identify a significant association between rs11178997 (TPH2) and PTSD. Our findings are contradictory to those of Goenjian et al. 2012 who found a significant correlation between rs11178997 and all PTSD clusters, and findings of Cao et al. 2014 who found significant association between rs11178997 and avoidance symptoms only in women. The negative findings concerning rs11178997 and depression in our study are in line with the findings of Goenjian et al. (2012), and contradictory to the study of Van Den Bogaert et al. (2006) who found a significant association for the TPH2 SNP rs11178997 with unipolar depression among patients in Sweden.

The second SNP of the TPH2 gene that was analysed in this study (rs1386494), was tested in relation to depression. We did not find a significant association between this SNP and depression. Our results are contradictory to those of Zill et al. (2004).

There are several limitations to our study. First of all, within our PTSD group, we found individuals who no longer met the criteria for PTSD (the lifetime PTSD) and those who met the criteria for current PTSD. This reduced the sample size which in turn reduced the statistical power. The second limitation is the lack of epigenetic analyses of the investigated genes such as methylation pattern. Epigenetic processes are known to affect the biological response to trauma. The nominal significant associations of the HTR1A gene variation rs6295 with lifetime PTSD and other comorbid pathology did not withstand Bonferroni correction, thus making our study only exploratory and hypothesis generating.

Although candidate gene association studies are the most commonly used approach in investigations of the genetics of PTSD, depression and other psychiatric disorders (Smoller, 2016), the results of such studies are mainly inconsistent and contradictory. Inconsistencies may be due to many factors such as methodological differences between studies, small sample sizes, the study of a limited number of genes or SNPs within genes, results that may differ related to the genetical background of the study populations, bias due to samples comprising various ethnicities, different types of trauma, the complex nature of the disorders, and a publication bias towards positive results (Cornelis et al. 2010, Koenen et al. 2008, Koenen et al. 2013, Goenjian et al. 2012). However, negative findings do not necessarily rule out the role of a particular gene in a particular disorder (Cornelis et al. 2010).

\section{CONCLUSION}

Considering that candidate gene studies yield contradictory results, we propose the use of Genome Wide Association Studies (GWAS) due to their hypothesisfree approach to disorders and the investigation of whole genomes instead of single candidate genes. This kind of approach, with large samples included may be more appropriate for studying the genetics of complex disorders such as PTSD and other comorbid disorders.

\section{Acknowledgements:}

We thank all the participants and their families without whose idealistic and enthusiastic support the study would not have been possible. We also would like to thank at Sarajevo: the Association of Women Victims of War and Bakira Hasecic, the Association of Physically Handicapped, Zilko Buljugija, Zoran Budimlija, MD, PhD, Jasminka Krehic, MD, PhD, Elvira Sabanovic, RSN and Subhija Gusic; in Kosovo: Feride Rushiti, MD, Selvije Izeti, MSc, Vjosa Devaja, MD, Melita Kallaba, MD from Kosova Rehabilitation Center for Trauma Survivors- KRCT; Emirjeta Kumnova, Veprore Shehu from Medica Kosova; Zahrije Podrimqaku Subashi from the Association of Political Prisoners, Kadire Tahiraj from the Center for Promotion of Women's Rights; Arbërore Ulaj, MD, Teuta Haxhiu, MD and Drita Gashi, MD, for their assistance in recruiting and interviewing participants; at Zagreb: Mirica Mavracic, Zoran Bradas, Zrinka Mirkovic and Maja Mezak Herceg for technical assistance in drawing blood and extracting DNA; at Tuzla: the staff of the Department of Transfusion of University Clinical Center of Tuzla, and the staff of the Department of Psychiatry, in particular Emina Hujdur, Medin Omerašević and Avdo Šakušić, MD for technical support and Maja Brkić and Sandra Zornić for their assistance in data collection; at Würzburg: Carola Gagel for technical assistance with extracting DNA. Thanks are highly deserved by and gratefully extended to Peter Riederer as spiritus rector who brought the consortium together. The study was funded by the DAAD program Stability Pact for South Eastern Europe and supported by the DFG-funded RTG 1253 (speaker Pauli) as well as the DFG-funded CRC-TRR58 (projects C02 Domschke, Deckert, and Z02 Deckert, Domschke).

\section{Conflict of interest: None to declare.}

\section{Contribution of individual authors:}

Each author has actively participated in the international research project (see Acknowledgments) and, therefore, has substantially contributed to the development and publication of this manuscript.

\section{References}

1. Almli LM, Fani N, Smith AK \& Ressler KJ: Genetic approaches to understanding posttraumatic stress disorder. Int J Neuropsychopharmacol 2014; 17:355-370

2. American Psychiatric Association: Diagnostic and Statistical Manual of Mental Disorder. 5th Edition. APA, Washington, DC, 2013

3. Baehne CG, Ehlis AC, Plichta MM, Conzelmann A, Pauli $P$, Jacob $C$ et al.: TPH2 gene variants modulate response control processes in adult ADHD patients and healthy individuals. Mol Psychiatry 2009; 14:1032-1039 
4. Benko A, Lazary J, Molnar E, Gonda X, Tothfalusi L, Pap $D$, et al.: Significant association between the $C(-1019) G$ functional polymorphism of the HTR1A gene and impulsivity. Am. J. Med. Genet 2010; 153B:592-599. doi:10.1002/ajmg.b.31025

5. Boyajyan A, Avetyan D, Hovhannisyan L \& Mkrtchyan G: Genetics of Posttraumatic Stress Disorder - Candidate Genes and Their Implication in the Disease-Associated Molecular Pathomechanisms, A Fresh Look at Anxiety Disorders, Dr. Federico Durbano (Ed.), InTech, 2015. DOI: 10.5772/60443. Available from:

https://www.intechopen.com/books/a-fresh-look-atanxiety-disorders/genetics-of-posttraumatic-stressdisorder-candidate-genes-and-their-implication-in-thedisease-assoc

6. Cao C, Wang L, Wang R, Qing Y \& Zhang J: TPH2 genotype is associated with PTSD's avoidance symptoms in Chinese female earthquake survivors. Psychiatric Genetics 2014; 24:257-261

7. Chipman P, Jorm AF, Tan X, Easteal S: No association between the serotonin-1A receptor gene single nucleotide polymorphism rs6295C/G and symptoms of anxiety or depression, and no interaction between the polymorphism and environmental stressors of childhood anxiety or recent stressful life events on anxiety or depression. Psychiatr Genet 2010; 20:8-13

8. Cornelis MC, Nugent NR, Amstadter AB, \& Koenen KC: Genetics of post-traumatic stress disorder: Review and recommendations for genome-wide association studies. Current Psychiatry Reports 2010; 12:313-326

9. De Yong JT, Komproe IH, Van Ommeren M, El Masri M, Araya $M$, Khaled $N$ et al.: Lifetime events and posttraumatic stress disorder in 4 post conflict settings. JAMA 2001; 286:555-562

10. Domschke K: Patho-genetics of posttraumatic stress disorder. Psychiatr Danub 2012; 24:267-273

11. Domschke K, Braun M, Ohrmann P, Suslow T, Kugel H, Bauer $J$ et al.: Association of functional $-1019 C / G$ 5HT1A polymorphism with prefrontal cortex and amygdala activation measured with 3 TfMRI in panic disorder. Int $J$ Neuropsychopharmacol 2006; 9:349-355

12. Donaldson ZR, le Francois B, Santos TL, et al.: The functional serotonin la receptor promoter polymorphism, rs6295, is associated with psychiatric illness and differences in transcription. Translational Psychiatry 2016; 6: e746- doi:10.1038/tp.2015.226

13. Goenjian AK, Bailey JN, Walling DP, Steinberg AM, Schmidt D, Dandekar U \& Noble EP: Association of TPH1, TPH2, and 5HTTLPR with PTSD and depressive symptoms. Journal of Affective Disorders 2012, 140:244-52

14. Hettema JM, An SS, van den Oord EJC, Neale MC, Kendler KS, Chen X: Association Study Between the Serotonin 1A Receptor (HTR1A) Gene and Neuroticism, Major Depression, and Anxiety Disorders. American journal of medical genetics Part B, Neuropsychiatric genetics: the official publication of the International Society of Psychiatric Genetics 2008; 147B:661-666. doi:10.1002/ajmg.b.30656

15. Illi A, Setala-Soikkeli E, Viikki M, Poutanen O, Huhtala H, Mononen N, et al.: 5-HTR1A, 5-HTR2A, 5-HTR6, TPH1 and TPH2 polymorphisms and major depression. Neuroreport 2009; 20:1125-1128
16. Jakovljevic M, Brajkovic L, Jaksic N, Loncar M, Aukst Margetic B, Lasic D: Posttraumatic stress disorder from different perspectives (PTSD): a transdisciplinary integrative approach. Psychiatr Danub 2012; 24:246-255

17. Kennedy AP, Binder EB, Bowman D, Harenski K, Ely T, Cisler JM et al.: A Common TPH2 Haplotype Regulates the Neural Processing of a Cognitive Control Demand. Am J Med Genet Part 2012; B 159B:829-840

18. Kessler RC, Sonnega A, Bromet E, Hughes M, Nelson CB: Posttraumatic Stress Disorder in the National Comorbidity Survey. Arch Gen Psychiatry. 1995; 52:1048-1060. doi:10.1001/archpsyc.1995.03950240066012

19. Kilpatrick DG, Resnick $H S$, Milanak ME, Miller MW, Keyes KM, Friedman MJ: National Estimates of Exposure to Traumatic Events and PTSD Prevalence Using DSM-IV and DSM-5 Criteria. Journal of traumatic stress 2013; 26:537-547. doi:10.1002/jts.21848

20. Kishi T, Yoshimura R, Fukuo Y, Okochi T, Matsunaga S, Umene-Nakano $W$ et al.: The serotonin $1 A$ receptor gene confer susceptibility to mood disorders: results from an extended meta-analysis of patients with major depression and bipolar disorder. Eur Arch Psychiatry Clin Neurosci 2013; 263:105-118

21. Koenen KC, Moffitt TE, Caspi A, Gregory A, Harrington $H$ \& Poulton R: The Developmental Mental-Disorder Histories of Adults With Posttraumatic Stress Disorder: A Prospective Longitudinal Birth Cohort Study. J Abnorm Psychol 2008; 117:460-466. doi:10.1037/0021$843 X .117 .2 .460$

22. Koenen KC, Duncan LE, Liberzon I and Ressler KJ: From candidate genes to genome-wide association: the challenges and promise of posttraumatic stress disorder genetic studies. Biological psychiatry 2013; 749:634-6

23. Kulenovic AD, Agani F, Avdibegovic E, Jakovljevic M, Babic D, Kucukalic A et al.: Molecular Mechanisms of Posttraumatic Stress Disorder (PTSD) as a Basis for Individualized and Personalized Therapy: Rationale, Design and Methods of the South Eastern Europe (SEE)PTSD study. Psychiatr Danub 2016; 28 2:154-63

24. Le Francois B, Czesak M, Steubl D, Albert PR: Transcriptional regulation at a HTR1A polymorphism associated with mental illness. Neuropharmacology 2008; 55:977-985

25. Lemonde S, Turecki G, Bakish D, Du L, Hrdina PD, Bown $C D$ et al.: Impaired repression at a 5-hydroxytryptamine $1 A$ receptor gene polymorphism associated with major depression and suicide. J Neurosci 2003; 23:8788-8799. [PubMed: 14507979]

26. Lopes Cardozo B, Kaiser R, Gotway CA \& Agani F: Mental Health, Social Functioning, and Feelings of Hatred and Revenge of Kosovar Albanians one Year After the War in Kosovo. Journal of Traumatic Stress 2003; 16:351-60

27. Norris FH, Murphy AD, Baker CK, Perilla JL: Epidemiology of trauma and posttraumatic stress disorder in Mexico. J Abnorm Psychol 2003; 112:646-56

28. Priebe S, Bogic M, Ajdukovic D, Franciskovic T, Galeazzi GM, Kucukalic A et al.: Mental Disorders Following War in the BalkansA Study in 5 Countries. Arch Gen Psychiatry 2010; 67:518-528. doi:10.1001/archgenpsychiatry.2010.37

29. Richardson LK, Frueh BC, Acierno R: Prevalence estimates of combat- related post-traumatic stress disorder: critical review. Aust N Z J Psychiatry 2010; 44:4-19 
30. Savitz J, Lucki I, Drevets WC: 5-HT1A Receptor Function in Major Depressive Disorder. Progress in neurobiology 2009; 88:17-31. doi: 10.1016/j.pneurobio.2009.01.009

31. Smoller JW: The Genetics of Stress-Related Disorders: PTSD, Depression, and Anxiety Disorders. Neuropsychopharmacology 2016; 41:297-319. doi:10.1038/npp.2015.266

32. Stein MB, Jang KL, Taylor S, Vernon PA, Livesley WJ: Genetic and environmental influences on trauma exposure and post-traumatic stress disorder symptoms: a twin study. Am J Psychiatry 2002; 159:1675-1681. [PubMed: 12359672]

33. Straube B, Reif A, Richter J, Lueken U, Weber H, Arolt V et al.: The functional $-1019 \mathrm{C} / \mathrm{G}$ HTR1A polymorphysm and mechanisms of fear. Translational Psychiatry 2014; 4:e490

34. Van Den Bogaert A, Sleegers K, De Zutter S, Heyrman L, Norrback K, Adolfsson R et al.: Association of BrainSpecific Tryptophan Hydroxylase, TPH2, With Unipolar and Bipolar Disorder in a Northern Swedish, Isolated Population. Arch Gen Psychiatry 2006; 63:1103-1110. doi:10.1001/archpsyc.63.10.1103

35. Zill P, Baghai TC, Zwanzger P, Schule C, Eser D, et al.: SNP and haplotype analysis of a novel tryptophan hydroxylase isoform (TPH2) gene provide evidence for association with major depression. Mol Psychiatry 2004; 9:1030-1036

Correspondence:

Afërdita Goçi Uka, MD, PhD candidate

Department of Psychiatry, University Clinical Centre of Kosovo

Str, Hile Mosi, nr 11, 10000 Prishtina, Kosovo

E-mail: aferditauka@hotmail.com 